\title{
Research on Hot-side Radiation Intensity of Semiconductor Refrigeration
}

\author{
Yunfeng Pang \\ School of Energy and Building Engineering, Harbin University of Commerce, China \\ 76456974@qq.com
}

Keywords: Semiconductor refrigeration; Refrigeration performance; Hot-side radiation intensity; Water cooling radiation

Abstract. The hot-side radiation intensity is an important factor of the semiconductor refrigeration performance. This article first selected three radiation ways: the air cooling radiation, the heat pipe radiation as well as the water cooling radiation, and then conducted the experimental study to the three radiation ways, obtaining conclusion that the effect of refrigeration was the best under the water cooling radiation. Then under the best radiation, the water-cooled radiation, it conducted experimental study of the radiation intensity, changing the radiation intensity by changing the hot-side water flow, and selected six groups of radiation intensities to carry on the experiment, and discovered the influence rule of hot-side radiation intensity to the performance of semiconductor refrigeration.

\section{Preface}

The effect of hot-side radiation in the process of semiconductor refrigeration will directly affect the cooling performance of semiconductor refrigeration. According to the laws of the semiconductor refrigeration, the temperature of hot-side in the process of semiconductor refrigeration has greatly influence the amount of heat and cold transfer. Poor performance of hot-side radiation will rise the hot-side temperature, thereby greatly reduce the capacity of semiconductor refrigeration. In certain electrical flow, by reducing the hot-side temperature can reduce heat transfer of hot-side to cold-side. Only make the heat discharged in time, to maintain low temperature of hot-side, the cold-side can continuously cooling, so hot-side radiation is the key, reduce the temperature difference between hot-side and cold-side is an effective method to improve the performance of semiconductor refrigeration.

\section{The Cooling Ways of Semiconductor Refrigeration}

At present, there are a lot of study about hot-side radiation of semiconductor refrigeration ${ }^{[1 \sim 8]}$. And the heat dissipation of semiconductor refrigeration mainly have: air natural convection, air forced convection cooling, water cooling, heat pipe heat transfer and phase-changing boiling heat transfer, etc $^{[6]}$.

Air Natural Convection. Air natural convection refer to the radiator dissipate heat to the environment by air natural convection, so as to achieve the purpose of cooling/heating. Because of its smaller power, it mainly used in some position where is narrow or noise limit strictly. But this disadvantage of heat dissipation is that the heat transfer coefficient is lower and the cooling effect is poorer, therefore this way cannot be widely used. Some small semiconductor devices adopt air natural convection, this need cooling fin of some forms as heat exchanger ${ }^{[6,7]}$.

The Air Forced Convection. Air forced convection refer to install an axial flow fan at the end of heat sink basing on the natural convection. After using forced convection radiator, the coefficient of convective heat transfer is far higher than that of natural convection heat transfer, so under the same cooling power, forced convection area will shrink a lot accordingly. The heat transfer effect of this cooling way is better, therefore this way is more widely applied, and it is mainly used for cooling fan, small air conditioner and air cooling dehumidification. But forced air cooling calculation must consider a number of additional conditions, such as air velocity, structure size of fin, blackness and surface roughness, so calculation process is more complex ${ }^{[6,7]}$. 
Water Cooling. Water cooling refers to connect a cooling water tank in the hot-side of the semiconductor refrigeration device, taking away hot-side heat continuously through the water in the cooling water pipe. The efficiency of this method is so high, its heat transfer coefficient are about one hundred times than air natural convection. When the hot-side of the semiconductor refrigeration device use the tank, because of its high heat transfer coefficient between water and the radiator, and the specific heat of water is bigger, so the cooling effect is good, the size of the heat exchanger is also greatly reduced accordingly. While water cooling radiator has a fault, it is easy to begrime in water-cooled surface, this reduce the heat transfer performance, but it is widely used for its remarkable cooling effect ${ }^{[6,7]}$.

Heat Pipe Heat Exchanger. Heat transfer is difference between heat pip and usual heat exchanger, The temperature difference of both sides in the process of working is not big, Thus this form a long zone of constant temperate along the tube axis. For refrigeration thermopile's structure mode, the heat flux of hot-side is large, so it requires that the radiator has good heat transfer efficiency. While the heat pipe radiators have some advantages, such as small volume, light weight and strong heat transfer capability, so it is very ideal to be heat dissipating way of semiconductor refrigeration device. But heat pipe has a drawback, which is very sensitive to gravity heat pipe, so it is used limited ${ }^{[6]}$.

Phase Transition Boiling Heat Transfer. Phase transition boiling heat transfer refer to use some certain substances to absorb heat and maintain constant temperature in the case of phase change, which cool the hot-side of the semiconductor refrigeration, this method mainly include the latent heat of vaporization and the latent heat of fusion, which are mainly suitable for intermittent working situation. Because the heat transfer coefficient of boiling heat transfer is high, so the heat dissipation effect of phase transition boiling is better, heat dissipating capacity per unit area and per unit time is bigger, the cooling intensity is more higher, therefore the hot-side temperature of semiconductor device is less, the temperature difference between hot-side and cold-side is smaller, the performance of refrigeration is better ${ }^{[6]}$.

\section{The Experimental Study of Three Different Cooling Ways}

Semiconductor refrigeration device absorb heat to cool at the cold-side, discharge a lot of heat at the hot-side at the same time, this is a kind of high heat flux density device. The hot side must use a certain cooling way to take away heat, which can produce good cooling effect. This experiment determined the effect of different heat dissipation ways to thermopile refrigerating.

Due to water cooling is widely used, The effect of water cooling is remarkable, and the heat dissipation effect of heat pipe is ideal, so in this experiment, three kinds of commonly used thermal radiation were used respectively: air-cooled, water cooling, and heat pipe, Then respectively determinate the cold and hot side temperature of semiconductor thermopile, and the lowest temperature which cooling space can reach. Comprise three cooling ways' effect to the cooling properties of semiconductor refrigeration. Three kinds of cooling worked in the same voltage and electric flow: $U=15 \mathrm{v}, \mathrm{I}=5 \mathrm{a}$, and each group of experimental measurement data parameters was the same: the hot-side temperature $\mathrm{T}_{\mathrm{h}}$, the cold-side temperature $\mathrm{T}_{\mathrm{C}}$, and cold room temperature of semiconductor $\mathrm{T}_{\mathrm{P}}$ along with the change of time. The data recorded once per minute, until the hot and cold side temperature was stabilization.

The Experimental Research of Air Cooling. Air cooling way of this study used is air forced convection heat transfer of above cooling ways, heat dissipation of hot-side used fin and fan for cooling. The heat dissipation fin was clingy in the hot-side of semiconductor thermopile, middle position daubed thermal conductive silicone, fixed on the cold side copper block with screws, axial flow fan fixed on the top of the heat dissipation fin. After the experimental apparatus installed, connect the circuit. Then start the regulated dc power supply to test after checked correctly.

Fig. 1 is that the curve of cold and hot side temperature and cold room temperature along with the change of time $t$ under air cooling heat dissipation. It can be seen that at the beginning of the experiment, semiconductor thermopile hot and cold-side temperature were both $23.7{ }^{\circ} \mathrm{C}$. within 1 
minute, the cold-side temperature dropped from $23.7{ }^{\circ} \mathrm{C}$ to $20.9{ }^{\circ} \mathrm{C}$, dropped by $2.8{ }^{\circ} \mathrm{C}$, but hot-side temperature rose sharply, increased from $23.7{ }^{\circ} \mathrm{C}$ to $50.1{ }^{\circ} \mathrm{C}$, increased by $26.4{ }^{\circ} \mathrm{C}$ within 1 minute. Experiment for 5 minutes, the hot-side reached the highest temperature of $53.6{ }^{\circ} \mathrm{C}$, the cold-side temperature dropped to $18.8{ }^{\circ} \mathrm{C}$. After 60 minutes, the temperature of cold and hot side tended to equilibrium, the cold-side temperature maintained at about $5.1{ }^{\circ} \mathrm{C}$, the hot-side temperature maintained at about $52.3{ }^{\circ} \mathrm{C}$.

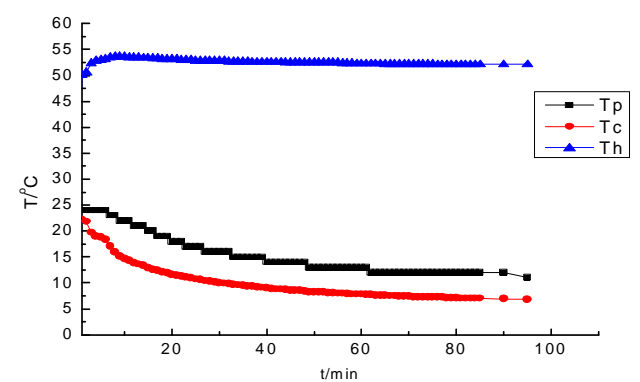

Fig.1. The curve of cold and hot side temperature and cold room temperature along with the change of time $t$ under air cooling heat dissipation

The Experimental Research of Heat Pipe. Heat pipe is sensitive to gravity. On the principle, heat pipe can work in any direction, but due to overcome the gravity, its performance will decline in working. the heat flow is given, when the hot-side position is higher than the cold-side position, the fluid of core fluid absorption move upward by forced to overcome gravity, thermal resistance will increase, on the other hand, thermal resistance will down. While the use of heat pipe must use fan, this experiment choosed dc axial flow fan.

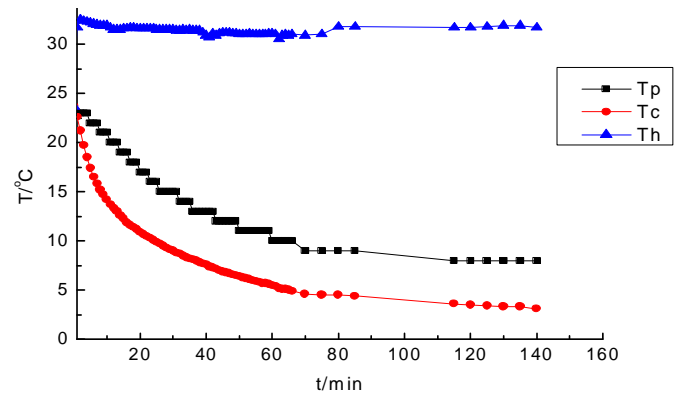

Fig.2. Cold and hot side temperature and cold room temperature curve along with the change of time $t$ under heat pipe radiation

Fig. 2 is cold and hot side temperature and cold room temperature curve along with the change of time $t$ under heat pipe radiation. It can be seen that at the beginning of the experiment, the hot and cold side temperature of semiconductor thermopile were both $23.7^{\circ} \mathrm{C}$. with the increase of time, the temperature of hot-side raised sharply and cold-side temperature and cold room temperature gradually declined, after 60 minutes, cold and hot side temperature and cold room temperature tended to equilibrium, the cold-side temperature maintained at about $3.1{ }^{\circ} \mathrm{C}$, the temperature of hot-side maintained at about $31.3{ }^{\circ} \mathrm{C}$, the temperature of the cold room maintained at $8{ }^{\circ} \mathrm{C}$.

Water Cooling Experimental Research.In water experiments, the cooling device is water cooling plate, its size: $9 \mathrm{~cm}$ long, $8 \mathrm{~cm}$ wide, $2 \mathrm{~cm}$ thick. Adopt the aluminum to enhance heat transfer. There are four waterways in plate, up and down are two water mouths of import and export, one side connect inlet pipe, another connect outlet pipe. Take the flow rate of import $9.17 \mathrm{ml} / \mathrm{s}$, water temperature of import is $12{ }^{\circ} \mathrm{C}$. Measured the cold and hot side temperature and room temperature of semiconductor thermopile are shown in Fig.3.

It can be seen that within two minutes before, the hot-side temperature raised sharply to the highest point $26.3{ }^{\circ} \mathrm{C}$, with the increase of time $t$, the hot-side temperature reduced; instead it showed that the effect of the cooling water to hot side was outstanding. As you can see, the hot-side temperature eventually tended to about $22.1{ }^{\circ} \mathrm{C}$, and the cold-side temperature tended to $8.5^{\circ} \mathrm{C}$ or so, cold room temperature constant- $2{ }^{\circ} \mathrm{C}$. 


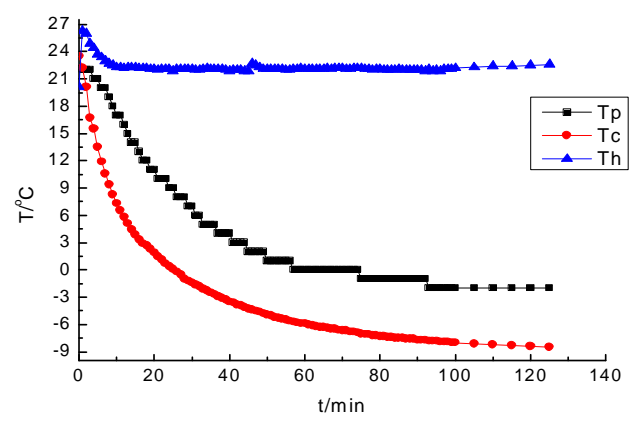

Fig.3. Cold and hot side temperature and cold room temperature curve along with the change of time $t$ under water cooling

The Comprehensive Study of Different Hot-side Radiation Ways to the Cooling Performance. comprehensively study the experimental results of three cooling ways, 1 represent air cooling heat dissipation, 2 represent the heat pipe cooling, 3 represent the water cooling heat dissipation.

Fig. 4 is the cold-side temperature curve along with the change of time $t$ under three kinds of cooling ways. It can be seen after 120 minutes, the cold-side temperature of air cooling stabilize in $7.2{ }^{\circ} \mathrm{C}$; cold-side temperature stabilized in $3.1{ }^{\circ} \mathrm{C}$ under heat pipe cooling, lower than air cooling heat dissipation low $4.1{ }^{\circ} \mathrm{C}$; And under water cooling, cold-side temperature reached $7.1{ }^{\circ} \mathrm{C}$.

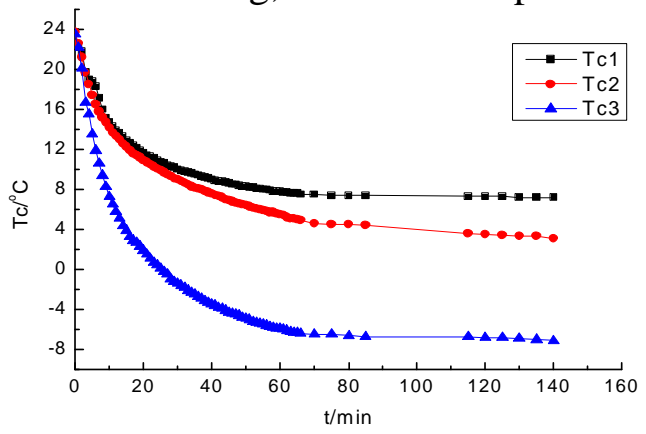

Fig.4. The cold-side temperature curve along with the change of time $t$ under three kinds of cooling ways

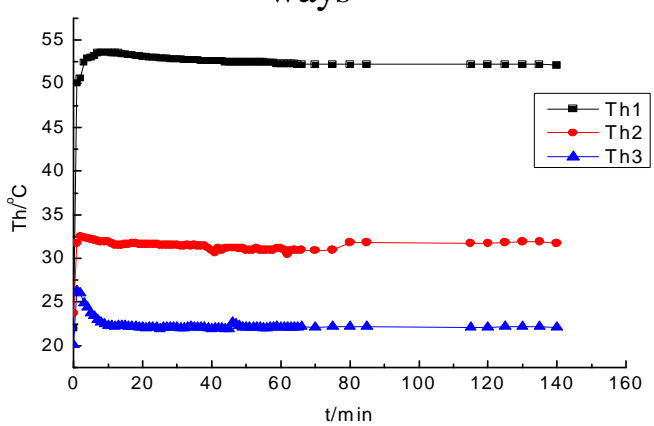

Fig.5. The hot-side temperature curve along with the change of time $t$ under three cooling ways

Fig. 5 is the hot-side temperature curve along with the change of time $t$ under three kinds of cooling ways. It can be seen after 120 minutes, hot-side temperature of air cooling is the highest, it ultimately stabilized in $52{ }^{\circ} \mathrm{C}$; under heat pipe radiator, the hot-side temperature decreased, finally stabilized in about $32{ }^{\circ} \mathrm{C}$, lower than that of air cooling heat dissipation $20{ }^{\circ} \mathrm{C}$; And under water cooling, the hot-side temperature reached $22^{\circ} \mathrm{C}$, respectively lower than water cooling $20{ }^{\circ} \mathrm{C}$ and heat pipe radiator $30{ }^{\circ} \mathrm{C}$.

It can be obtained through experiments, the effect of water-cooling heat dissipation is the most significant, then is heat pipe, and the last is air cooling. That is to say, the better the heat radiation is, the lower the temperature of hot and cold side drop, and the cold room temperature of semiconductor can reach the lower temperature. But whether increase water flow (cooling intensity) can achieve lower cold-side temperature and cold room temperature is lower? The following experiment is done under the best way of heat dissipation, measured the performance changes of semiconductor refrigeration under different cooling intensity. 


\section{The Effect of Cooling Intensity to the Cooling Performance}

The Scheme Determination of Cooling Intensity Experiment. As you can see from the above experiments, the effect of water cooling is the most significant, so choose water-cooling experiment to measure the effect of the cooling intensity to the cooling performance. By changing the flow of hot-side to change cooling intensity, water flow gradually increased from $9.17 \mathrm{ml} / \mathrm{s}$, take six different flow of $9.17 \mathrm{ml} / \mathrm{s}, 14.75 \mathrm{ml} / \mathrm{s}, 22 \mathrm{ml} / \mathrm{s}, 36.67 \mathrm{ml} / \mathrm{s}, 68.75 \mathrm{ml} / \mathrm{s}$ and $91.67 \mathrm{ml} / \mathrm{s}$ for experiment respectively, each set of test both text under the same voltage $U=12 \mathrm{v}$, then measure the cold-side temperature curve along with the change of time, and draw 6 groups of curve in the same figure, compared to determine the effect rule of semiconductor refrigeration's hot-side cooling intensity to the cooling performance. Record once every1 minutes, until the cold-side temperature of semiconductor thermopile stability.

The Cooling Intensity of the Results of Research. Draw the curve of cold and hot side temperature of semiconductor thermopile and cold room temperature along with the change of time $t$ in the same figure under the cooling intensity of 6 groups. Determine the rule of semiconductor thermopile's hot and cold side temperature and semiconductor cold room temperature changing with the time $\mathrm{t}$.

Fig.6 is that the curve of semiconductor thermopile's hot-side temperature along with the change of time $t$ under different water flow. It can be seen that at the start of the experiment, the hot-side temperature of semiconductor thermopile raised, but then immediately declined, the temperature gradually tended to stabilize in about 10 minutes, after increasing the water flow, the finally stable temperature of hot-side decreased, but it can be seen that when the water flow increased to $68.75 \mathrm{ml} / \mathrm{s}$ later, the decreasing trend of hot-side's finally constant temperature was slow, eventually stabilized in around $16{ }^{\circ} \mathrm{C}$. That is to say, with the increase of heat intensity, the temperature of hot-side ultimately reduced, but when the cooling intensity increased to a certain value, the influence of increasing heat intensity to the hot-side temperature will tend to be slow.

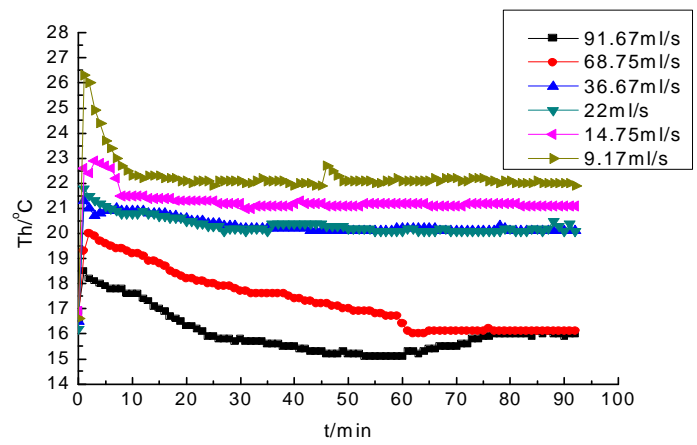

Fig.6. Semiconductor thermopile's hot-side temperature chart along with the change of time $t$ under different water flow

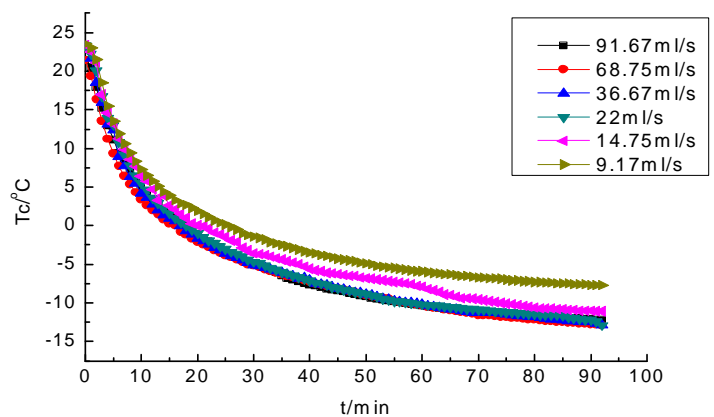

Fig.7. Semiconductor thermopile's cold-side temperature chart along with the change of time $t$ under different water flow

Fig.7 is semiconductor thermopile's cold-side temperature chart along with the change of time $t$ under different water flow. It can be seen that with the increase of time, the cold-side temperature dropped, temperature gradually became stabilization after 60 minutes, after increasing the water flow, the constant temperature of cold-side finally decreased, but it can be seen that when water flow increased to $22 \mathrm{ml} / \mathrm{s}$, the decreasing trend of cold side's constant temperature was slow, the constant 
temperature was $12.5^{\circ} \mathrm{C}$ or so in the end. That is to say, the cold-side temperature reduced with the increase of heat intensity, but when the cooling intensity increased to a certain value, the impact of the increasing heat intensity to the cold side temperature will tend to be slow.

By the above experiments, it can be concluded that with the increase of the heat intensity (hot water flow), cold-side temperature of semiconductor refrigeration space can achieve decreases, but when cooling intensity (hot water flow) increase to a certain value, the cold-side temperature will not reduce, and reach a constant value. Analyze its reason, mainly due to that after the semiconductor material is selected, the thermoelectric properties are also identified, so when the semiconductor thermopile is selected, its cooling performance is also stability, and it is only related to the optimal value coefficient of semiconductor material, but not through unlimited increase cooling intensity of hot side to change the performance of semiconductor refrigeration. So, in practical application, we should improve the cooling system of hot side and reasonable optimization design, to avoid and reduce the unnecessary waste.

\section{Conclusions}

Because the heat radiation capacity of the semiconductor refrigeration system is equal to the sum of the refrigerating capacity and the input power, so solve the heat dissipation to refrigeration efficiency is the key. At present, the heat radiation ways of semiconductor refrigeration mainly have: air natural convection, forced convection air cooling, water cooling, heat pipe heat transfer and phase change boiling heat transfer, etc.

(1) This paper has carried on the theoretical and experimental research on the hot side cooling way, selected three kinds of commonly used cooling ways: air cooling, water cooling and heat pipe cooling, then conducted experiment research at the same working voltage and power flow, it is concluded that: under water cooling way, semiconductor refrigeration performance is the most significant, then is the heat pipe, finally is air cooling.

(2) This paper test different effect rule of heat dissipation to the performance of semiconductor refrigeration under the best dissipating way (water cooling). Conclusion: with the increase of the heat intensity (hot water flow), cold side temperature of semiconductor refrigeration space can achieve decreased, but when the cooling intensity (hot water flow) increased to a certain value, the cold side temperature will no longer continue to reduce, but reached a constant value.

\section{References}

[1]Yang Shi, etc. Journal of zhengzhou institute of light industry (natural science edition), 2003,18(2):77 79. In Chinese

[2] Jiancheng Zhang. Journal of southeast university (natural science edition), 2000,30(5):45 48. In Chinese

[3] Shenglong Xu, etc. Practical testing techniques, 1996,2:14 17. In Chinese

[4]Zetao Chi , etc. Journal of natural science of heilongjiang university, 1996,13(2):66 68. In Chinese

[5] Duqi Yuan, Journal of low temperature physics, 2002,24(3):39 41. In Chinese

[6] Wanyi Hong. Fuzhou university graduate student outstanding papers, 2006,6:23 25. In Chinese

[7] Desheng Xu. Semiconductor refrigeration and application technology [M]. Shanghai: Shanghai jiaotong university press, 1992. In Chinese

[8] Ying Wang, Yunfeng Pang, Gang Yin. Research on the Performance of Solar Semiconductor Refrigeration [J]. The 4th Asian Conference on Refrigeration and Air-conditioning, 2009:602-605. 